\title{
Sperm evolution in the family Alestidae with comparative data for the genus Chalceus (Ostariophysi: Characiformes)
}

\author{
Júlio César de O. Santana ${ }^{1}$, Daniela Calcagnotto² and Irani Quagio-Grassiotto ${ }^{3^{*}}$
}

\begin{abstract}
Spermiogenesis and spermatozoa in six genera of the African family Alestidae plus the Neotropical genus Chalceus are described. Spermiogenesis is quite similar in all Alestidae and is identified as Type I and its variants. In Type I spermiogenesis, the flagellum of earliest spermatids lies lateral to the nucleus, and rotation of the nucleus towards the centriolar complex is observed. Nuclear rotation is complete reaching 90 degrees in Bryconalestes longipinnis, Brachypetersius altus, Brycinus imberi, B. lateralis, and Alestopetersius compressus; and is incomplete reaching 20 degrees in Micralestes acutidens and Rhabdalestes rhodesiensis. Spermatozoa morphology varies from a medial nucleus with fibrillar chromatin in the most basal genus Brycinus to a strongly eccentric nucleus with highly condensed chromatin in the more derived Rhabdalestes and Micralestes. Chalceus has a very similar spermatozoon to that found in Brycinus sharing the fibrillar aspect of the chromatin in the nucleus. This feature is so far only observed in these two genera among African and Neotropical characiform fishes.
\end{abstract}

A espermiogênese e os espermatozoides de seis gêneros que compõem a família Alestidae mais o gênero Chalceus são descritos. A espermiogênese é muito similar em todas as espécies de Alestidae analisadas e pode ser considerada como sendo o Tipo I e suas variações. Neste tipo de espermiogênese, o flagelo das espermátides iniciais dispõe-se lateral ao núcleo. A rotação do núcleo em direção ao complexo centriolar está presente. A rotação nuclear é completa, atingindo 90 graus, em Bryconalestes longipinnis, Brachypetersius altus, Brycinus imberi, B. lateralis e Alestopetersius compressus; incompleta, atingindo 20 graus, em Micralestes acutidens e Rhabdalestes rhodesiensis. A morfologia dos espermatozoides de Alestidae varia desde o núcleo medial com cromatina fibrilar no gênero Brycinus, considerado mais basal, até o núcleo muito excêntrico com cromatina altamente compactada, nos gêneros Rhabdalestes e Micralestes, considerados mais derivados dentro de Alestidae. Chalceus possui um espermatozoide muito similar a Brycinus, compartilhando entre eles o aspecto fibrilar da cromatina no núcleo. Esta característica até o momento só foi observada nestes dois gêneros dentre os Characiformes Africanos e Neotropicais.

Key words: African Fish, Ostariophysi, Spermatozoa, Systematics, Ultrastructure.

\section{Introduction}

The Characiformes is currently divided into 23 families distributed in Neotropical and African freshwaters. The family Alestidae, an African representative of the order, includes 117 valid species (Eschmeyer \& Fong, 2014). The first mention of the family Alestidae was made by Géry (1977) based on an artificial classification. The monophyly of the family was proposed for the first time through a phylogenetic approach by Ortí \& Meyer (1997) using molecular data and including only the genera Alestes, Hydrocynus, and Phenacogrammus. Since then, other proposals for alestid relationships were presented based on morphological (Murray \& Stewart, 2002; Zanata \& Vari, 2005) and molecular datasets (Calcagnotto et al., 2005; Arroyave \& Stiassny, 2011). Zanata \& Vari (2005) performed the most comprehensive morphological analysis including 19 alestid genera and provided a huge source of anatomical information and synapomorphies for intrafamilial relationships. Calcagnotto et al. (2005), in a study of suprafamilial

\footnotetext{
${ }^{1}$ Universidade Estadual de Campinas (UNICAMP), Programa de Pós-Graduação em Biologia Celular e Estrutural. Prédio da PG-IB, Bloco O, Caixa Postal 6109, 13083-865 Campinas, SP, Brazil. juliosantanas@yahoo.com.br

${ }^{2}$ Universidade de São Paulo (USP), Departamento de Genética e Biologia Evolutiva, Instituto de Biociências. Rua do Matão, 277, 05508900 São Paulo, SP, Brazil. dcalcag@terra.com.br

${ }^{3}$ Universidade Estadual Paulista “Júlio de Mesquita Filho” (UNESP), Instituto de Biociências, Departamento de Morfologia. Rubião Júnior, s/n, 18618-970 Botucatu, SP, Brazil. iraniqg@ibb.unesp.br
} 
relationships within characiforms, included 14 alestid genera in a phylogenetic analysis using a molecular dataset with nuclear and mitochondrial genes. Arroyave \& Stiassny (2011) presented the most recent and comprehensive phylogenetic study of the family including 19 genera and 53 taxa with a molecular dataset of two nuclear (SH3PX3 and myh6) and two mitochondrial (COI and cyt-b) genes. Although this last study found the Alestidae as non-monophyletic the authors discussed the possibility of this result as an artifact of missing data of the genus Lepidarchus.

Although the family Alestidae has been considered monophyletic in most analysis, not all of the genera included in the family are considered monophyletic (for a review, see Arroyave \& Stiassny, 2011). For example, Brycinus is polyphyletic in Calcagnotto's et al. (2005) and Arroyave \& Stiassny's (2011) analyses. Additionally in Arroyave \& Stiassny (2011) Bathyaethiops, Alestopetersius, and Rhabdalestes were recovered as paraphyletic given their placement with respect to members of the genera Brachypetersius, Tricuspidalestes, and Hemigrammopetersius respectively, suggesting that taxonomic revision might be necessary for these genera. A controversial question remaining is the phylogenetic position of the genus Chalceus. This genus has been strongly supported as the sister-group of all other so-called “Characidae" in Calcagnotto's et al. (2005) study. However in Zanata \& Vari's (2005) morphological study the genus Chalceus is placed as the sister-group of all remaining Alestidae. Later, Arroyave \& Stiassny (2011) found Chalceus more closely related to South American characins than to African alestids. Therefore, a more extensive phylogenetic analysis should be performed to highlight the position of Chalceus within Neotropical and African characiform fishes.

Recent studies have shown that reproductive characters could be a valuable source of evidence for relationships among fish taxa (Santana et al., 2013). Above and beyond its descriptive significance, a better understanding of this type of data is of major interest owing to its potential as an additional source of characters for future phylogenetic inferences. In view of recent phylogenetic studies of the Alestidae and the controversial phylogenetic position of Chalceus between morphological and molecular datasets, we herein describe the spermiogenesis and spermatozoa ultrastructure of representatives of the Alestidae plus Chalceus (sensu Arroyave \& Stiassny, 2011) to provide an additional source of characters for future phylogenetic analysis. Information from these character complexes is discussed.

\section{Material and Methods}

Examined specimens belong to the collections of the American Museum of Natural History, New York (AMNH), Museu de Zoologia da Universidade de São de Paulo, São Paulo (MZUSP), South African Institute for Aquatic Biodiversity, Grahamstown (SAIAB), and National Museum of Natural History, Smithsonian Institution, Washington, D.C.-
(USNM). Descriptions of sperm features are based on observations at the ultrastructural level of gametic cells from testis of adult males of Alestopetersius compressus (Poll \& Gosse, 1963) (AMNH 242455), Brachypetersius altus (Boulenger, 1899) (SAIAB 77705), Brycinus imberi (Peters, 1852) (SAIAB 67678), Brycinus lateralis (Boulenger, 1900) (SAIAB 81252), Bryconalestes longipinnis (Günther, 1864) (USNM 298659), Chalceus epakros Zanata \& Toledo-Piza, 2004 (MZUSP 77595), Micralestes acutidens (Peters, 1852) (SAIAB 97248), Rhabdalestes rhodesiensis (Ricardo-Bertram, 1943) (SAIAB 65354).

Testes of specimens, previously fixed in $4 \%$ formaldehyde and stored in $70 \%$ alcohol, were gradually rehydrated in a decreasing ethanol concentration to distilled water. Once rehydrated, the material was re-fixed overnight in $2 \%$ glutaraldehyde and 4\% paraformaldehyde in $0.1 \mathrm{M} \mathrm{pH} 7.2$ Sorensen phosphate buffer. The samples were post-fixed in the dark for $2 \mathrm{~h}$ in $1 \%$ osmium tetroxide in the same buffer, stained in block with an aqueous solution of 5\% uranyl acetate for $2 \mathrm{~h}$, dehydrated in acetone, embedded in araldite, and sectioned and stained with a saturated solution of uranyl acetate in $50 \%$ ethanol and lead citrate. Electron micrographs were obtained using a Tecnai ${ }^{\circledR}$ transmission electron microscope.

\section{Results}

Spermiogenesis in the family Alestidae. Details of spermiogenesis are consistent across the alestid species examined; therefore we present a general description of the process for all species (Fig. 1). In early spermatids the cytoplasm symmetrically encircles the nucleus, which displays diffuse homogenous chromatin and has a circular outline (Fig. 1a-b). The centriolar complex lies laterally to the nucleus and is anchored to the plasma membrane (Fig. 1a-b). The proximal centriole is anterior and oblique to the distal centriole (Fig. 1a). The distal centriole differentiates into the basal body and organizes the axoneme of the flagellum. The nucleus rotates towards the centriolar complex (Fig. 1c, d, e) with nuclear rotation varying from 90 degrees considered complete in Bryconalestes longipinnis, Brachypetersius altus, Brycinus imberi, B. lateralis, and Alestopetersius compressus, to 20 degrees in Micralestes acutidens and Rhabdalestes rhodesiensis which is considered incomplete. A depression is formed in the nuclear outline at the level of the centriolar complex that penetrates it (Fig. 1d, e, f). Simultaneous to nuclear rotation, the cytoplasm projects towards the initial segment of the flagellum forming the cytoplasmic canal and midpiece (Fig. 1d, f). The midpiece contains the mitochondria, forming vesicles and cytoplasmic canal housing the initial segment of the flagellum (Fig. 1d, f).

Spermiogenesis in Chalceus epakros. Due to the poor condition of the material from this species it was not possible to recover information about spermiogenesis. 
a

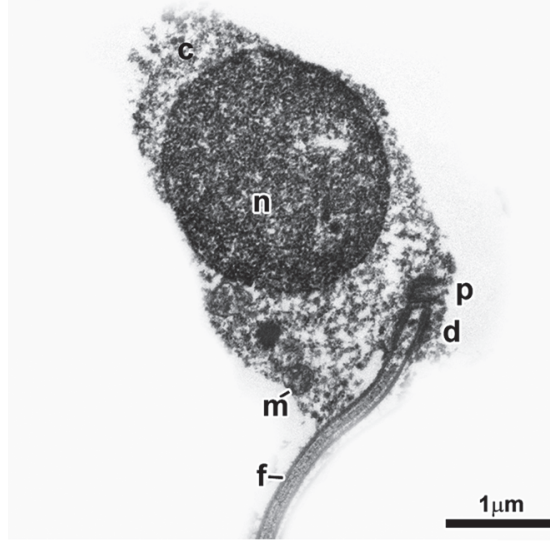

d

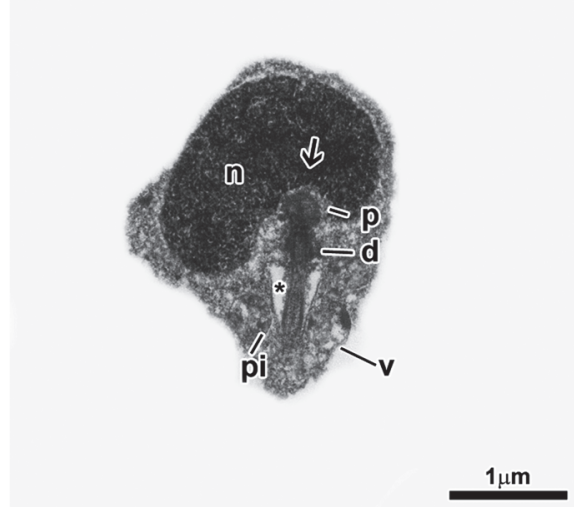

b

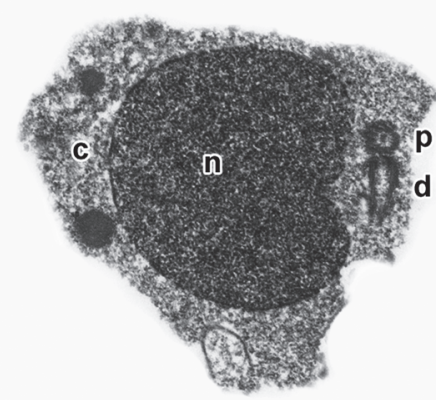

e

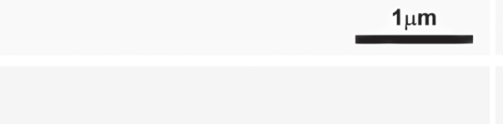

C
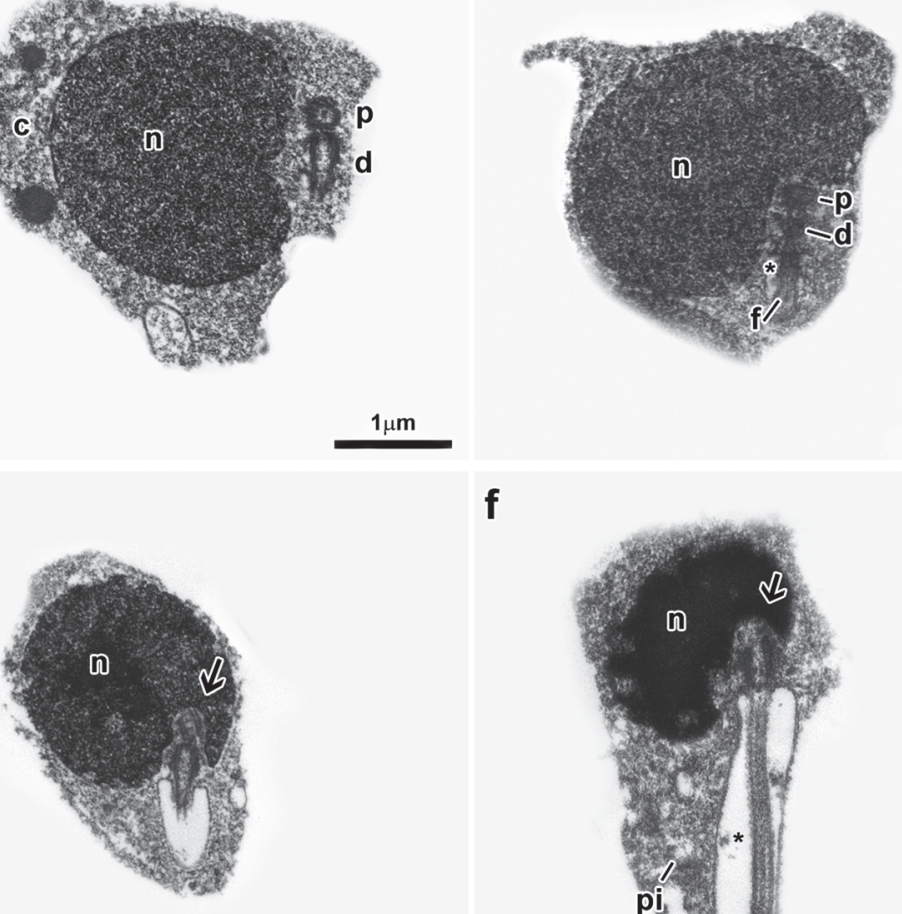

$1 \mu \mathrm{m}$

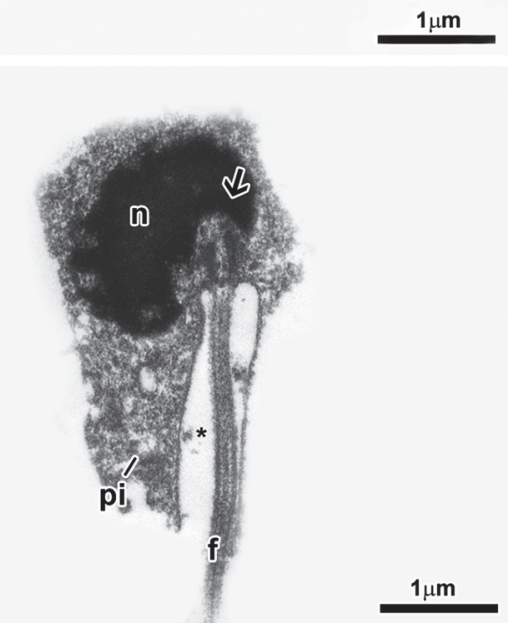

Fig. 1. Spermiogenesis process of the Alestidae. Figure subunits are longitudinal sections of spermatids corresponding to (a, b) Brycinus lateralis, (c) Brycinus imberi, (d) Brachypetersius altus, (e) Alestopetersius compressus, (f) Micralestes acutidens. The flagellum is initially lateral to the nucleus. The nuclear rotation towards the flagellar axis is present. The nuclear rotation can be complete reaching 90 degrees as represented by the late spermatid of Alestopetersius compressus (e), or incomplete reaching about 20 degrees as occurs in the late spermatid of Micralestes acutidens (f). Legends: c: cytoplasm, d: distal centriole, f: flagellum, m: mitochondria, n: nucleus, p: proximal centriole, pi: midpiece, v: vesicle, asterisk: cytoplasmic canal, arrow: nuclear fossa.

Sperm of the family Alestidae: Bryconalestes longipinnis (Fig. 2). Nucleus spherical, lying medial to the flagellar axis, measures about $1.3 \mu \mathrm{m}$ in diameter and is filled with floccular chromatin (Fig. 2a-c). Nuclear rotation is complete reaching 90 degrees (Fig. 2c). Nuclear outline with one deep-branched depression (nuclear fossa) (Fig. 2c, d). Proximal and distal centrioles located inside the nuclear fossa (Fig. 2c), with the proximal centriole anterior to the distal centriole (Fig. 2c). Proximal centriole at right angle relative to the distal centriole (Fig. 2c). Flagellum medial to slightly eccentric, relative to the nucleus (Fig. 2b, c). Midpiece is asymmetric and contains the mitochondria and a few vesicles (Fig. 2a-c). A cytoplasmic sleeve is present at the end of the midpiece and measures about $0.58 \mu \mathrm{m}$ in length (Fig. 2a, g). The mitochondria are spherical and distributed in all areas of the midpiece except in the cytoplasmic sleeve region (Fig. 2e, f). The vesicles are spherical (Fig. 2e). Along the length of the cytoplasmic canal, a few concentric membranous rings are found (Fig. 2g). The flagellum contains a classic axoneme $(9+2)$ and has lateral fins (Fig. 2h).
Alestopetersius compressus (Fig. 3). Nucleus spherical, lying eccentric to the flagellar axis, measures about $1.7 \mu \mathrm{m}$ in diameter and is filled with highly condensed granular chromatin (Fig. 3a, b). Nuclear rotation is complete reaching 90 degrees. Nuclear outline with one concave depression (nuclear fossa) (Fig. 3a). Proximal centriole and distal centriole located inside the nuclear fossa (Fig. 3a), with the proximal centriole anterior to the distal centriole (Fig. 3a). Proximal centriole is oblique relative to the distal centriole (Fig. 3a). Flagellum strongly eccentric relative to the nucleus. Midpiece is strongly asymmetric and contains the mitochondria and a few vesicles (Fig. 3a-c). The mitochondria are spherical distributed in all area of the midpiece (Fig. 3b-d). The vesicles are large and spherical (Fig. 3e). The flagellar membrane has some vesicles and the flagellum contains a classic axoneme $(9+2)$ and lacks lateral fins (Fig. 3f).

Brachypetersius altus (Fig. 4). Nucleus spherical, lying medial to the flagellar axis, measures about $1.6 \mu \mathrm{m}$ in diameter and is 

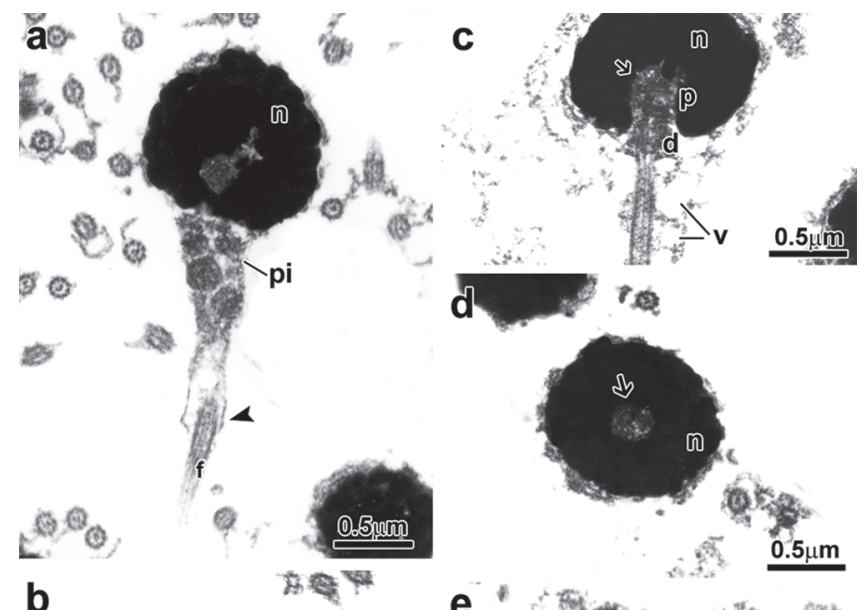

b

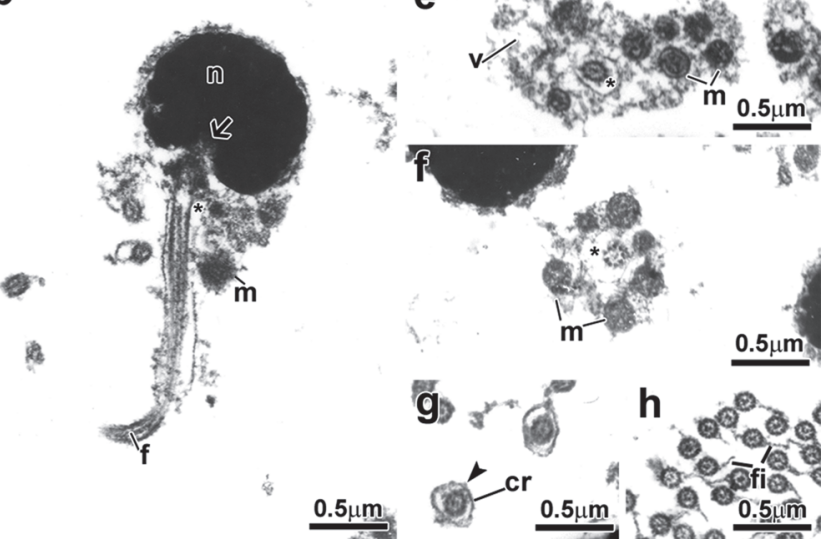

Fig. 2. Spermatozoon of Bryconalestes longipinnis. a, b, c: longitudinal sections. d, e, f, g, h: transverse sections from top to posterior region. The nucleus (n) is spherical and lies medial to the flagellum (f). The centriolar complex (p, d) and nuclear fossa (arrow) is medial. The proximal centriole (p) is in a right angle relative to the distal centriole (d). The cytoplasmic canal is present (asterisk). The midpiece (pi) is asymmetrical, and contains the spherical mitochondria (m), vesicles (v) and a cytoplasmic sleeve (arrowhead). The flagellum has lateral fins (fi). Legends: cr: concentric membranous rings, d: distal centriole, f: flagellum, fi: lateral fins, $m$ : mitochondria, $n$ : nucleus, p: proximal centriole, v: vesicle, asterisk: cytoplasmic canal, arrow: nuclear fossa, arrowhead: cytoplasmic sleeve.

filled with floccular chromatin (Fig. 4a-c). Nuclear rotation is complete reaching 90 degrees. Nuclear outline with one deepbranched depression (nuclear fossa) (Fig. 4a, d). Proximal and distal centrioles located inside the nuclear fossa (Fig. 4c), with the proximal centriole anterior to the distal centriole (Fig. 4c). Proximal centriole at right angle relative to the distal centriole (Fig. 4c). Flagellum medial to slightly eccentric relative to the nucleus (Fig. 4a). Midpiece is asymmetric and contains the mitochondria and a few vesicles. A cytoplasmic sleeve is present at the end of the midpiece and measures about $2.7 \mu \mathrm{m}$ in length (Fig. 4a, i). The mitochondria are a
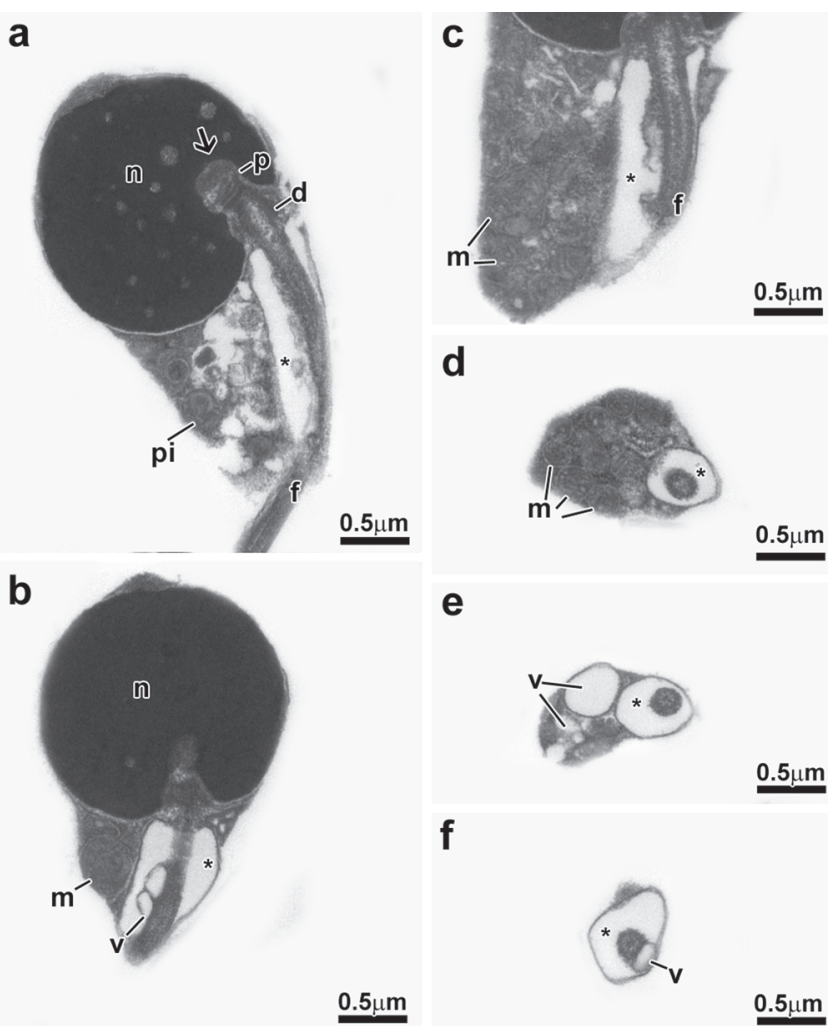

d

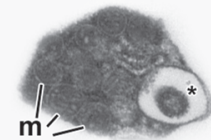

$0.5 \mu \mathrm{m}$

e

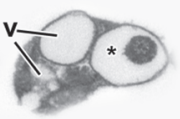

$\underline{0.5 \mu \mathrm{m}}$

$\mathbf{f}$

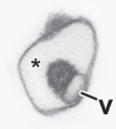

$0.5 \mu \mathrm{m}$

Fig. 3. Spermatozoon of Alestopetersius compressus. a, b, c: longitudinal sections. d, e, f: transverse sections from top to posterior region. The nucleus (n) is spherical and lies eccentric to the flagellum (f). The centriolar complex (p, d) and nuclear fossa (arrow) is eccentric. The proximal centriole (p) is oblique relative to the distal centriole (d). The cytoplasmic canal is present (asterisk). The midpiece (pi) is strongly asymmetrical, and contains the spherical mitochondria (m) and vesicles (v). The flagellar membrane has some vesicles and the flagellum. Legends: d: distal centriole, f: flagellum, m: mitochondria, $\mathrm{n}$ : nucleus, p: proximal centriole, v: vesicle, asterisk: cytoplasmic canal, arrow: nuclear fossa.

branched or in "c" shape and distributed in all area of the midpiece except in the cytoplasmic sleeve region (Fig. 4e-h). The vesicles are spherical (Fig. 4f). Along the length of the cytoplasmic canal, a few concentric membranous rings are found (Fig. 4g). The flagellum contains a classic axoneme $(9+2)$ and lacks lateral fins.

Brycinus imberi (Fig. 5) and Brycinus lateralis (Fig. 6). Nucleus spherical, lying medial to the flagellar axis, measures about $1.5 \mu \mathrm{m}$ in diameter in both B. imberi (Fig. 5a-f) and $B$. lateralis (Fig. 6a-e). Nucleus is filled with chromatin with a fibrillar aspect interspersed by electron-lucent areas (Figs. $5 \mathrm{a}, \mathrm{e}, 6 \mathrm{a}, \mathrm{d})$ and interconnected to larger areas of more condensed chromatin (Figs. 5a-f, 6a-e). Nuclear rotation is complete reaching 90 degrees. Nuclear outline with one deepbranched depression (nuclear fossa) (Figs. 5a, 6a). Proximal 

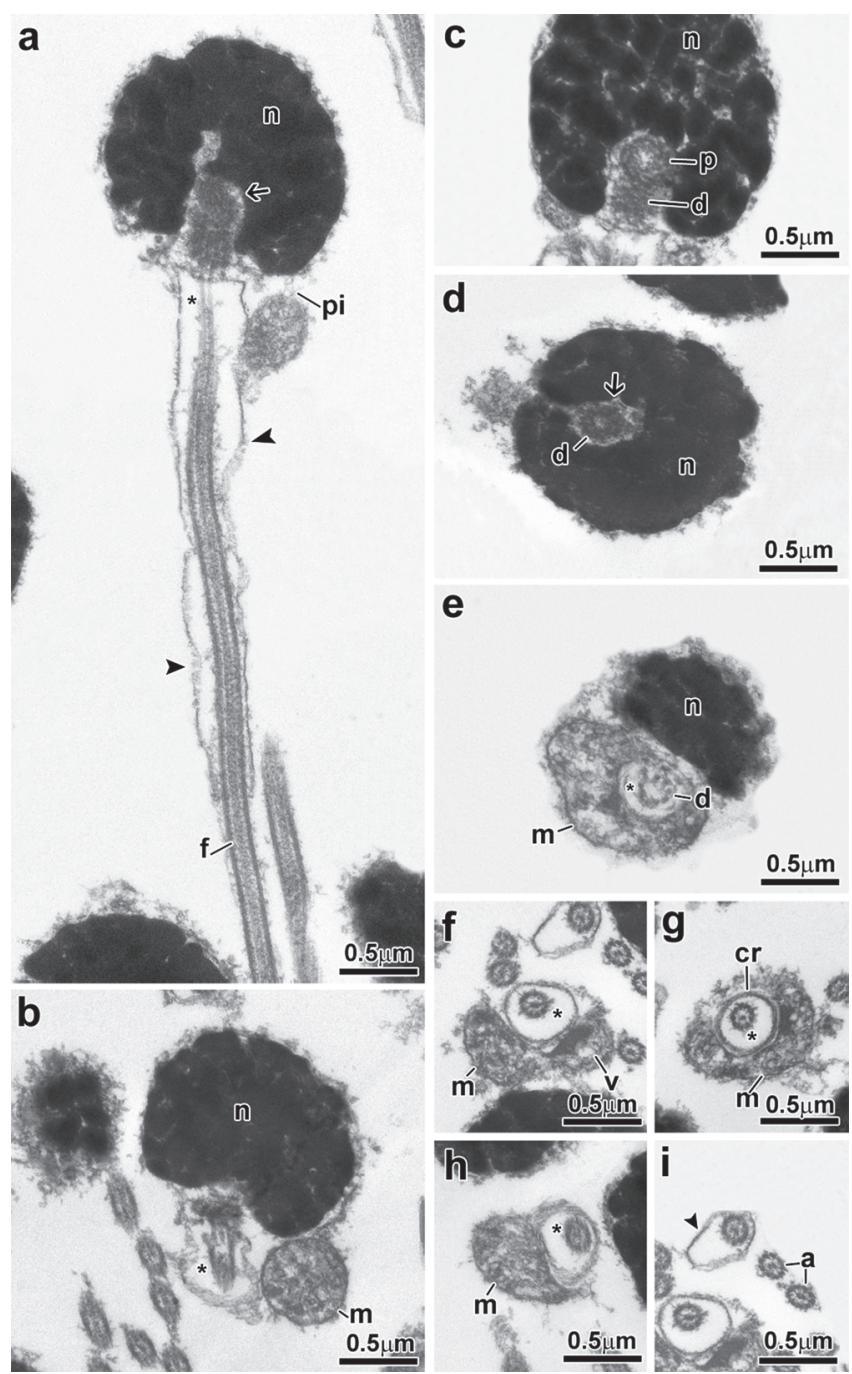

Fig. 4. Spermatozoon of Brachypetersius altus. a, b, c: longitudinal sections. d, e, f, g, h, i: transverse sections from top to posterior region. The nucleus (n) is spherical and lies medial to the flagellum (f). The centriolar complex (p, d) and nuclear fossa (arrow) is medial. The proximal centriole (p) is in a right angle relative to the distal centriole (d). The cytoplasmic canal is present (asterisk). The midpiece (pi) is asymmetrical, and contains the branched or " $\mathrm{c}$ " shape mitochondria (m), vesicles (v) and a cytoplasmic sleeve (arrowhead). Legends: a: axoneme, cr: concentric membranous rings, d: distal centriole, f: flagellum, m: mitochondria, n: nucleus, p: proximal centriole, v: vesicle, asterisk: cytoplasmic canal, arrow: nuclear fossa, arrowhead: cytoplasmic sleeve.

and distal centrioles located inside the nuclear fossa (Figs. 5a, c, d, 6a, c), with the proximal centriole anterior to the distal centriole (Figs. 5c, 6c). Proximal centriole at right angle relative to the distal centriole (Figs. 5c, 6c). Flagellum slightly eccentric relative to the nucleus. Midpiece is asymmetric and contains the mitochondria and a few vesicles (Figs. 5a, 6a). A cytoplasmic sleeve is present at the end of the midpiece of

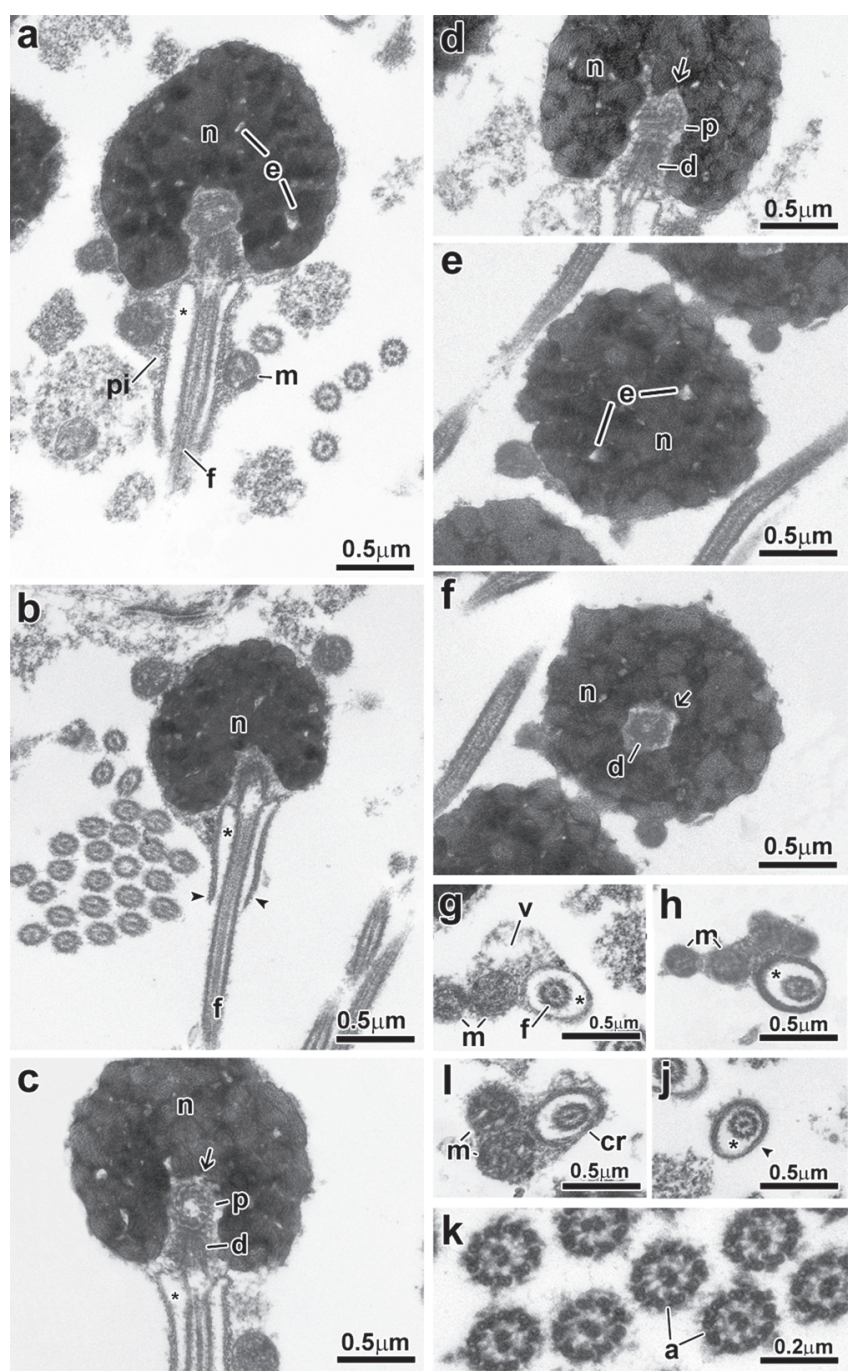

Fig. 5. Spermatozoon of Brycinus imberi. a, b, c, d: longitudinal sections. e, f, g, h, i, j, k: transverse sections from top to posterior region. The nucleus (n) is spherical and lies medial to the flagellum (f). The centriolar complex (p, d) and nuclear fossa (arrow) is medial. The proximal centriole (p) is in a right angle relative to the distal centriole (d). The cytoplasmic canal is present (asterisk). The midpiece (pi) is asymmetrical, and contains the spherical mitochondria $(\mathrm{m})$, vesicles $(\mathrm{v})$ and a cytoplasmic sleeve (arrowhead). Legends: a: axoneme, cr: concentric membranous rings, d: distal centriole, e: electronlucent areas, f: flagellum, m: mitochondria, $\mathrm{n}$ : nucleus, $\mathrm{p}$ : proximal centriole, v: vesicle, asterisk: cytoplasmic canal, arrow: nuclear fossa, arrowhead: cytoplasmic sleeve.

both species and measures about $0.37 \mu \mathrm{m}$ in length in $B$. imberi (Fig. 5b, j) and $2.82 \mu \mathrm{m}$ in B. lateralis (Fig. 6a, j). The mitochondria in both species are spherical and distributed in all area of the midpiece except in the cytoplasmic sleeve region (Figs. 5g-i, 6f-i). The vesicles are spherical in both species (Figs. 5g, 6h). Along the length of the cytoplasmic canal, a few concentric membranous rings are found (Figs. 5i, 6i). The 


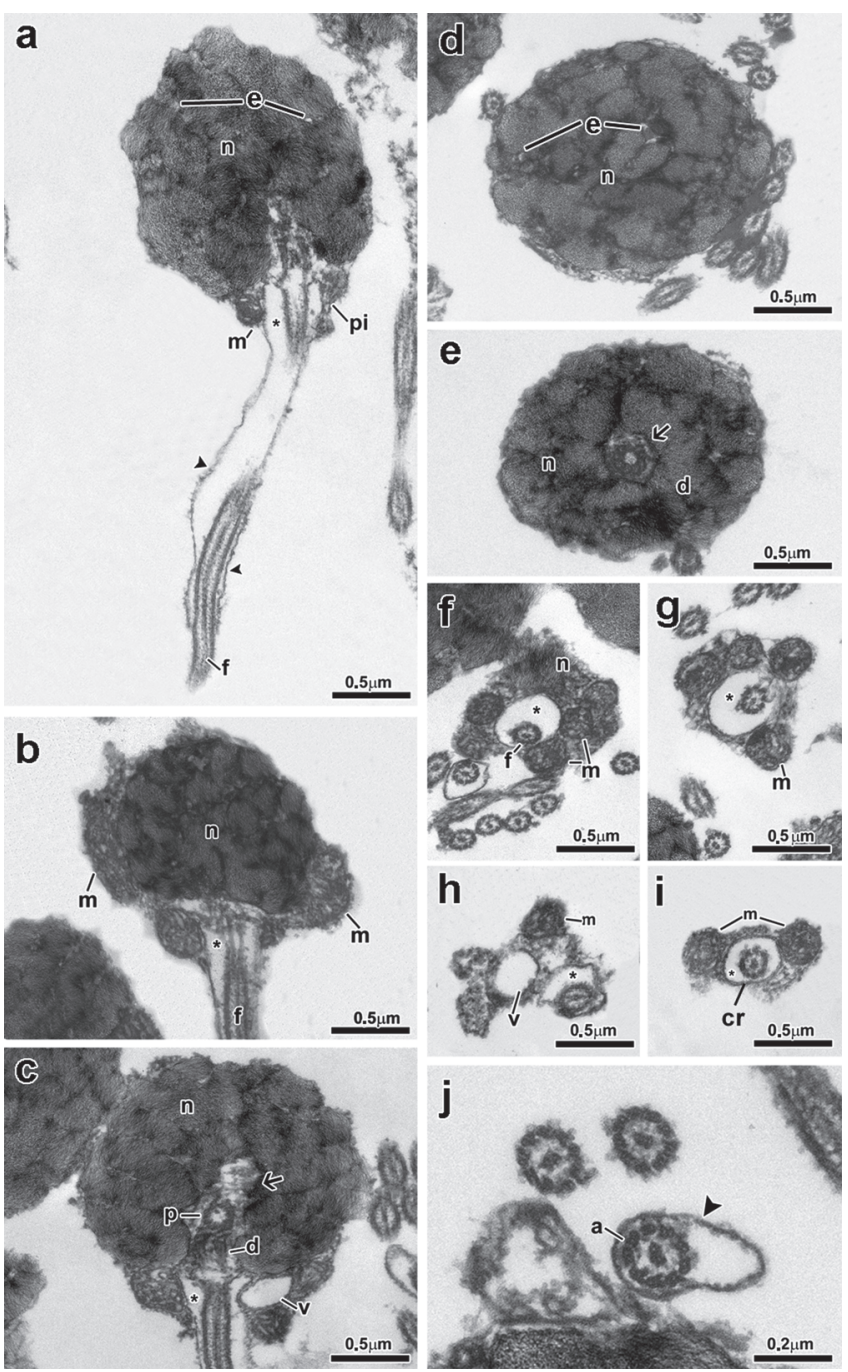

Fig. 6. Spermatozoon of Brycinus lateralis. a, b, c: longitudinal sections. d, e, f, g, h, i, j: transverse sections from top to posterior region. The nucleus (n) is spherical and lies medial to the flagellum (f). The centriolar complex (p, d) and nuclear fossa (arrow) is medial. The proximal centriole (p) is in a right angle relative to the distal centriole (d). The cytoplasmic canal is present (asterisk). The midpiece (pi) is asymmetrical, and contains the spherical mitochondria (m), vesicles (v) and a cytoplasmic sleeve (arrowhead). Legends: a: axoneme, cr: concentric membranous rings, d: distal centriole, e: electronlucent areas, f: flagellum, m: mitochondria, n: nucleus, $\mathrm{p}$ : proximal centriole, v: vesicle, asterisk: cytoplasmic canal, arrow: nuclear fossa, arrowhead: cytoplasmic sleeve.

flagellum contains a classic axoneme $(9+2)$ and lacks lateral fins (Figs. 5k, 6j).

Micralestes acutidens (Fig. 7). Nucleus spherical, lying strongly eccentric to the flagellar axis, measures about $1.6 \mu \mathrm{m}$ in diameter and is filled with highly condensed granular chromatin. Nuclear rotation is incomplete reaching about 20 degrees (Figs. 7a, b). Nuclear outline with one concave

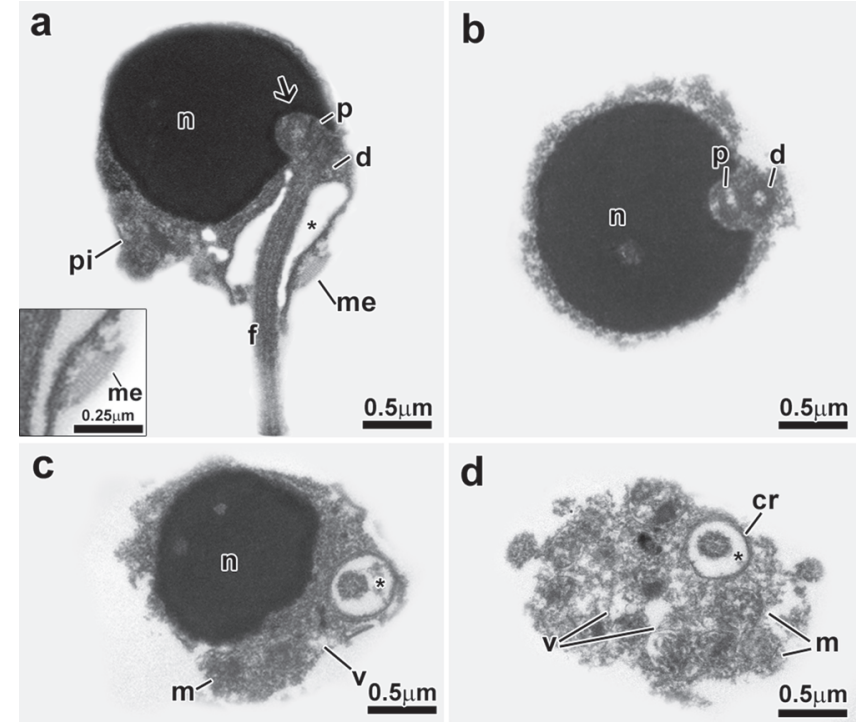

Fig. 7. Spermatozoon of Micralestes acutidens. a, a-inset: longitudinal sections. b, c, d: transverse sections from top to posterior region. The nucleus (n) is spherical and lies strongly eccentric to the flagellum (f). The centriolar complex (p, d) and nuclear fossa (arrow) is strongly eccentric. The proximal centriole (p) is lateral and perpendicular relative to the distal centriole (d). The cytoplasmic canal is present (asterisk). The midpiece (pi) is strongly asymmetrical, and contains the spherical mitochondria (m) and vesicles (v). The membrane of the midpiece (me) has a striated aspect along its length (a, a- inset). Legends: cr: concentric membranous rings, d: distal centriole, $\mathrm{f}$ : flagellum, $\mathrm{m}$ : mitochondria, me: membrane of the midpiece, n: nucleus, p: proximal centriole, v: vesicle, asterisk: cytoplasmic canal, arrow: nuclear fossa.

depression (nuclear fossa) (Fig. 7a). Proximal centriole inside the nuclear fossa and distal centriole outside the nuclear fossa (Fig. 7a, b), with the proximal centriole lateral and perpendicular relative to the distal centriole (Fig. 7a). Flagellum strongly eccentric relative to the nucleus (Fig. 7a). Midpiece is strongly asymmetric and contains the mitochondria and a few vesicles (Fig. 7a). The mitochondria are spherical, distributed in all area of the midpiece (Fig. 7a, c, d). The vesicles are spherical (Fig. 7c, d). Along the length of the cytoplasmic canal, a few concentric membranous rings are found (Fig. 7d). The membrane of the midpiece has a striated aspect along its length (Fig. 7a, a-inset). The flagellum contains a classic axoneme $(9+2)$ and lacks lateral fins.

Rhabdalestes rhodesiensis (Fig. 8). Nucleus spherical, lying strongly eccentric to the flagellar axis, measures about $1.6 \mu \mathrm{m}$ in diameter and is filled with highly condensed granular chromatin (Fig. 8a). Nuclear rotation is incomplete reaching about 20 degrees. Nuclear outline with one concave depression (nuclear fossa) (Fig. 8a). Proximal centriole inside the nuclear fossa and distal centriole is about one third inside 

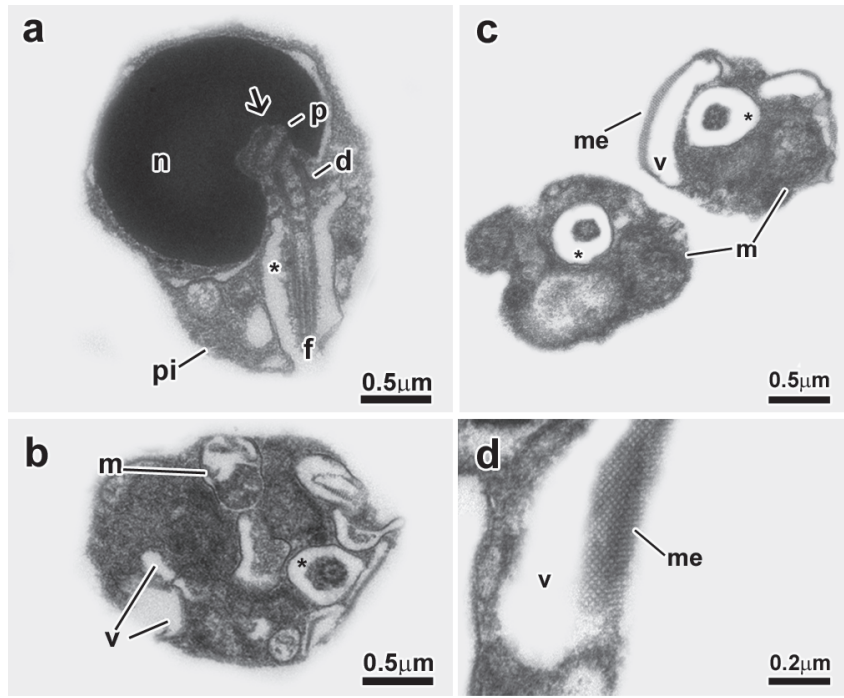

$\underline{0.2 \mu \mathrm{m}}$

Fig. 8. Spermatozoon of Rhabdalestes rhodesiensis. a, d: longitudinal sections. b, c: transverse sections from top to posterior region. The nucleus (n) is spherical and lies strongly eccentric to the flagellum (f). The centriolar complex (p, d) and nuclear fossa (arrow) is strongly eccentric. The proximal centriole (p) is anterior and oblique relative to the distal centriole (d). The cytoplasmic canal is present (asterisk). The midpiece (pi) is strongly asymmetrical, and contains the spherical mitochondria (m) and vesicles (v). The membrane of the midpiece (me) has a striated aspect along its length (c, d). Legends: d: distal centriole, f: flagellum, m: mitochondria, me: membrane of the midpiece, n: nucleus, p: proximal centriole, v: vesicle, asterisk: cytoplasmic canal, arrow: nuclear fossa.

it (Fig. 8a). The proximal centriole lies anterior to the distal centriole (Fig. 8a). The proximal centriole is oblique relative to the distal centriole (Fig. 8a). Flagellum is strongly eccentric relative to the nucleus (Fig. 8a). Midpiece is strongly asymmetric and contains mitochondria and vesicles (Fig. 8ac). The mitochondria are spherical and distributed in all area of the midpiece (Fig. 8a, c). The vesicles are large and spherical (Fig. 8b-d). The membrane of the midpiece has a striated aspect along its length (Fig. 8d). The flagellum contains a classic axoneme $(9+2)$ and lacks lateral fins.

Sperm of Chalceus epakros (Fig. 9). Nucleus spherical, lying medial to the flagellar axis, measures about $1.1 \mu \mathrm{m}$ in diameter (Fig. 9a, b). Nucleus filled with chromatin with a fibrillar aspect interspersed by electron-lucent areas and interconnected to larger areas of more condensed chromatin (Fig. 9a). Nuclear rotation is complete reaching 90 degrees. Proximal and distal centrioles located inside the nuclear fossa (Fig. 9a), with the proximal centriole anterior to the distal centriole (Fig. 9a). Proximal centriole at right or oblique angle relative to the distal centriole (Fig. 9a). Flagellum slightly eccentric to medial relative to the nucleus. Midpiece is asymmetric and contains the mitochondria and apparently no vesicles (Fig. 9a, b). A
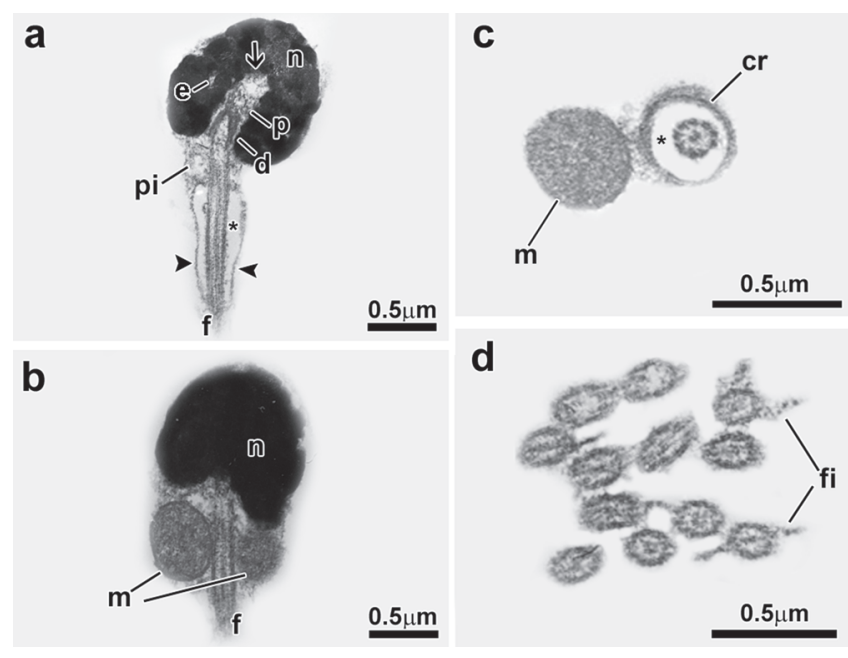

Fig. 9. Spermatozoon of Chalceus epakros. a, b: longitudinal sections. c, d: transverse sections from top to posterior region. The nucleus (n) is spherical and lies medial to the flagellum (f). The centriolar complex (p, d) and nuclear fossa (arrow) is medial. The proximal centriole (p) is in a right or oblique angle relative to the distal centriole (d). The cytoplasmic canal is present (asterisk). The midpiece (pi) is asymmetrical, and contains only one "c" shape mitochondria (m), vesicles (v) and a cytoplasmic sleeve (arrowhead). The flagellum has lateral fins (fi). Legends: cr: concentric membranous rings, d: distal centriole, e: electron-lucent areas, f: flagellum, fi: flagellar fins, $\mathrm{m}$ : mitochondria, n: nucleus, p: proximal centriole, v: vesicle, asterisk: cytoplasmic canal, arrow: nuclear fossa, arrowhead: cytoplasmic sleeve.

cytoplasmic sleeve is present at the end of the midpiece and measures about $0.8 \mu \mathrm{m}$ in length (Fig. 9a). Only one mitochondrion with "c" shape is surrounding the cytoplasmic canal (Fig. 9b, c). Along the length of the cytoplasmic canal, a few concentric membranous rings are found (Fig. 9c). The flagellum contains a classic axoneme $(9+2)$ and has lateral fins (Fig. 9d).

All the descriptions of the alestid spermiogenesis and spermatozoa "plus Chalceus spermatozoon are summarized in Table 1.

\section{Discussion}

Spermiogenesis in the Alestidae is of Type I, which is the most common among characiform fishes (see Burns et al., 2009, for a review). Type I spermiogenesis, as described by Mattei (1970), is characterized mainly by a lateral flagellum relative to the nucleus and the presence of a complete nuclear rotation towards the flagellar axis in the spermatids, reaching 90 degrees in the spermatozoon. Herein, complete nuclear rotation is observed in Alestopetersius, Bryconalestes, Brycinus, and Brachypetersius. Complete nuclear rotation was also described for Phenacogrammus interruptus 


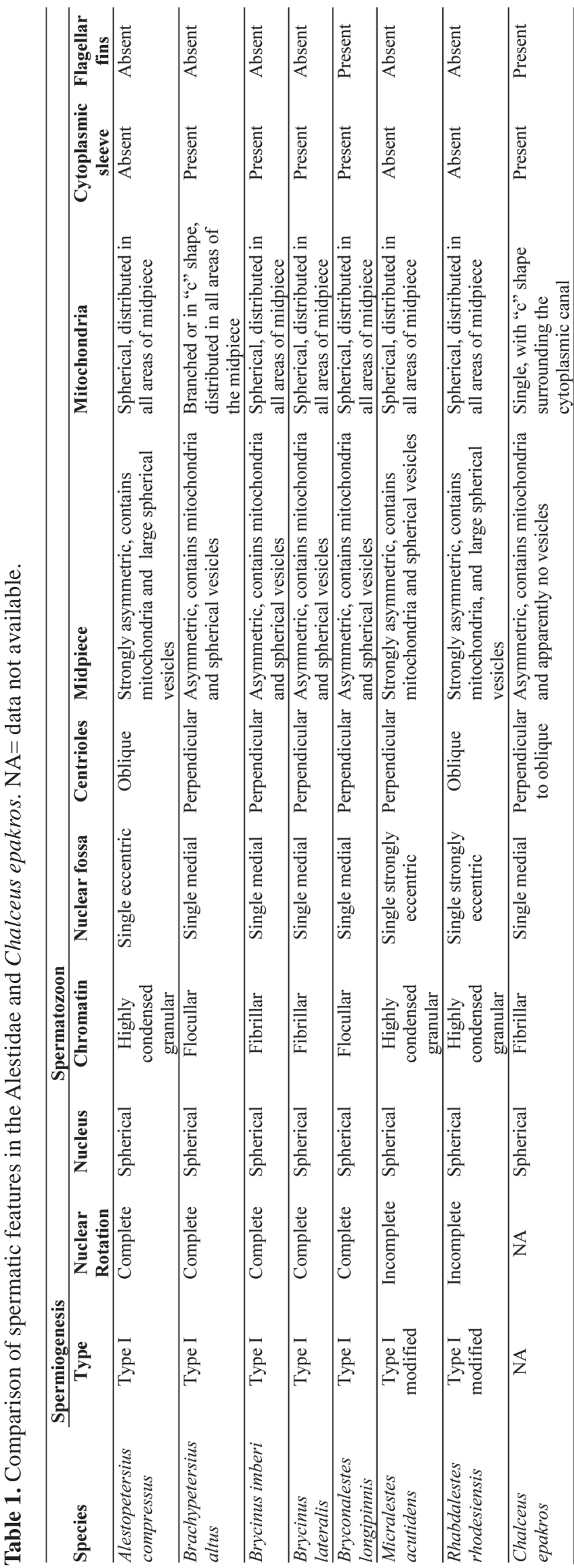

(Veríssimo-Silveira, 2007). In Micralestes and Rhabdalestes, however, nuclear rotation is incomplete reaching only about 20 degrees in the spermatozoa and could be considered as a derived variant of Type I spermiogenesis.

Sperm ultrastructure shows a few differences among alestid species. In all species analyzed the nucleus is spherical but varies in the pattern of chromatin compaction and position relative to the flagellar axis. In Brycinus imberi and B. lateralis, the nucleus is medial relative to the flagellar axis and the chromatin has a fibrillar aspect interspersed by electron-lucent areas and interconnected to larger areas of more condensed chromatin. This pattern of chromatin is so far only found in the genus Brycinus and Chalceus among characiform fishes with spermatozoon description available (review in Burns et al., 2009). In Bryconalestes and Brachypetersius the nucleus is medial relative to the flagellar axis and the chromatin has a floccular aspect. Micralestes and Rhabdalestes have a strongly eccentric nucleus and highly condensed granular chromatin. In Alestopetersius the nucleus is eccentric and has a highly condensed chromatin. These latter nuclear features were also found in Phenacogrammus interruptus (Veríssimo-Silveira, 2007).

The midpiece is asymmetrical in Bryconalestes, Brycinus, Brachypetersius, and also in Phenacogrammus interruptus (Veríssimo-Silveira, 2007), and strongly asymmetrical in Alestopetersius, Micralestes, and Rhabdalestes. In all species analyzed, the midpiece contains the mitochondria and vesicles. The mitochondria are spherical in all alestids examined herein except to Brachypetersius altus where it is ramified or in " $\mathrm{c}$ " shape and the vesicles vary from small to large in diameter and can be considered a species-specific feature (review in Burns et al., 2009). Chalceus epakros has only one mitochondrion in "c" shape and has no vesicles in the midpiece. Concentric membranous rings were found in the midpiece of Bryconalestes longipinnis, Brachypetersius altus, Brycinus imberi, B. lateralis, Micralestes acutidens, Rhabdalestes rhodesiensis, and Chalceus epakros. Flagellar fins were observed only in Bryconalestes longipinnis and Chalceus epakros. Sharin (2006) also described the presence of concentric membranous rings and flagellar fins in Alestes dentex. The presence of the cytoplasmic sleeve within alestids is observed in Bryconalestes longipinnis, Brachypetersius altus, Brycinus imberi, B. lateralis, and Alestes dentex (Sharin, 2006), and Chalceus epakros.

Arroyave \& Stiassny's (2011) phylogeny identified a clade "C" including the genera Alestopetersius, Bathyaethiops, Brachypetersius, Clupeocharax, Duboisialestes, Nannopetersius, Phenacogrammus, and Tricuspidalestes. Three genera included in clade "C" were investigated herein and the final shape of sperm of Alestopetersius and Phenacogrammus (Veríssimo-Silveira, 2007) are more similar to each other than to Brachypetersius. Alestopetersius and Phenacogrammus share highly condensed nuclear chromatin, an eccentric nucleus, and the presence of vesicles in the flagellar membrane. The sperm shape of Brachypetersius, and also of Bryconalestes (clade "D" of Arroyave \& Stiassny, 
2011), resembles the sperm of Brycinus in sharing a single medial nuclear fossa, asymmetric midpiece and presence of a cytoplasmic sleeve and could be more related to the basal genera in the family Alestidae as proposed by morphological phylogenetic analysis performed by Zanata \& Vari (2005). Presence of membrane of the midpiece with a striated aspect along its length has only been observed in Micralestes acutidens and Rhabdalestes rhodesiensis to date.

Descriptions of the sperm in this study represent a small number of alestid genera, but were selected to represent the morphological variation within the family and to include most basal and derived taxa from current phylogenies. These data suggest that nuclear rotation could be assigned to an evolutionary transformation series from complete, seen in the basal genera herein examined, and becoming incomplete in the more derived genera. Thus, the nucleus is medial in basal genera, such as Brycinus, and is strongly eccentric in more derived genera as Micralestes and Rhabdalestes (sensu Calcagnotto et al., 2005; Arroyave \& Stiassny, 2011). Sperm features of Chalceus epakros suggest it to be more closely related to the basal genus Brycinus than to other alestid included herein and Neotropical characiform fishes with spermatozoon description available.

\section{Acknowledgments}

We thank the Electron Microscopy Laboratory of IBB/ UNESP for allowing the use of their facilities. We also would like to thank Melanie Stiassny (American Museum of Natural History - AMNH), Paul Skelton (South African Institute for Aquatic Biodiversity - SAIAB), Osvaldo T. Oyakawa (Museu de Zoologia da Universidade de São Paulo - MZUSP) and Richard Vari (Division of Fishes, Department of Vertebrate Zoology, National Museum of Natural History, Smithsonian Institution, Washington, D.C. - USNM), for permissions to use the facilities and for donating gonadal tissues from specimens of the ichthyological collections. This study is part of a Ph.D. project by the first author supported by FAPESP (Fundação de Amparo à Pesquisa do Estado de São Paulo - Grant n 2010/01626-2).

\section{Literature Cited}

Arroyave, J. \& M. L. J. Stiassny. 2011. Phylogenetic relationships and the temporal context for the diversification of African characins of the family Alestidae (Ostariophysi: Characiformes): Evidence from DNA sequence data. Molecular Phylogenetics and Evolution, 60: 385-397.
Burns, J. R., I. Quagio-Grassiotto \& B. G. M. Jamieson. 2009. Ultrastructure of spermatozoa: Ostariophysi. Pp. 287-388. In: Jamieson, B. G. M. (Ed.). Reproductive biology and phylogeny of fish (Agnatha and Osteichthyes). Enfield, Science Publishers.

Calcagnotto, D., S. A. Schaefer \& R. DeSalle. 2005. Relationships among characiform fishes inferred from analysis of nuclear and mitochondrial gene sequences. Molecular Phylogenetics and Evolution, 36: 135-153.

Eschmeyer, W. N. \& J. D. Fong (Eds.). Genera, species, references. Available from: http://research.calacademy.org/research/ ichthyology/catalog/fishcatmain.asp/ (18 Mar 2014).

Géry, J. 1977. Characoids of the World. Neptune City, Tropical Fish Hobbyist Publications.

Mattei, X. 1970. Spermiogenése des poisson. Pp. 57-72. In: Baccetti, B. (Ed.). Comparative Spermatology. New York, Academic Press.

Murray, A. M. \& K. M. Stewart. 2002. Phylogenetic relationships of the African genera Alestes and Brycinus (Teleostei, Characiformes, Alestidae). Canadian Journal of Zoology, 80: 1887-1899.

Ortí, G. \& A. Meyer. 1997. The radiation of characiform fishes and the limits of resolution of mitochondrial ribosomal DNA sequences. Systematic Biology, 46: 75-100.

Santana, J. C. O., C. M. Baicere-Silva, P. Gusmão-Pompiani, R. C. Benine \& I. Quagio-Grassiotto. 2013. An assessment approach for application of spermatic data in phylogenetic analyses: within the genus Moenkhausia Eigenmann 1903 (Characiformes: Characidae). Acta Zoologica (Stockholm), 94: 335-354.

Sharin, A. A. B. 2006. Spermatogenesis and spermatozoon ultrastructure in the Nile pebblyfish Alestes dentex (Teleostei: Characiformes: Alestidae) in Egypt. World Journal of Zoology, 1: 1-16.

Veríssimo-Silveira, R. 2007. Ultraestrutura da espermiogênese e dos espermatozoides de peixes da Subordem Characoidei (Teleostei: Characiformes): uma abordagem filogenética. 2007. Unpublished Ph.D. Dissertation, Universidade Estadual Paulista "Júlio de Mesquita Filho", São Paulo, SP, 131 p.

Zanata, A. M. \& R. P. Vari. 2005. The family Alestidae (Ostariophysi, Characiformes): a phylogenetic analysis of a trans-Atlantic clade. Zoological Journal of the Linnean Society, 145: 1-144.

Submitted October 2, 2013 Accepted March 21, 2014 by George Mattox Published June 30, 2014 